\title{
Evaluation of laparoscopic rectosigmoidopexy for the treatment of complete rectal prolapse in children
}

\author{
Ahmed Mokhtar, Mohamed Abouheba, Sameh Shehata \\ Pediatric Surgery Department, Children's Hospital, Alexandria University, El-Shatby, Alexandria 21131, Egypt.
}

Correspondence to: Prof. Sameh Shehata, Pediatric Surgery Department, Children's Hospital, Alexandria University, El-Shatby, Alexandria 21131, Egypt. E-mail: drsamehs@yahoo.com

How to cite this article: Mokhtar A, Abouheba M, Shehata S. Evaluation of laparoscopic rectosigmoidopexy for the treatment of complete rectal prolapse in children. Mini-invasive Surg 2017;1:24-30.

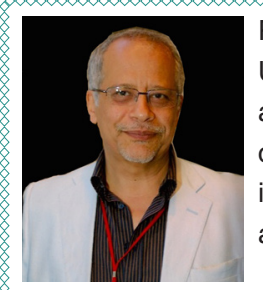

Prof. Sameh Shehata is working as professor and past chairman of Pediatric Surgery Department, Faculty of Medicine, University of Alexandria, Egypt. He is the past president of the Egyptian Association of Pediatric Surgeons. He has a wide international activity in the field of pediatric surgery; he is the president-elect of the WOFAPS, and the cochairman of the IPEG middle east chapter. He has given over 150 lectures both nationally and internationally and was invited as a guest lecture in many national associations congresses. He is among the editorial board of many national and international pediatric surgery journals including the JPS, PSI and International Journal of Urology.

\section{Article history:}

Received: 20-12-2016

Accepted: 07-03-2017

Published: 31-03-2017

Key words:

Laparoscopy,

rectopexy,

sigmoidopexy,

rectal prolapse,

children,

3-point fixation

\begin{abstract}
Aim: Rectal prolapse in children is a common condition in infancy and early childhood that usually responds to conservative measures. Surgery is reserved only for resistant cases that fail to respond to conservative measures. This study was designed to evaluate the efficacy of 3-point fixation concept (retrorectal dissection, rectopexy to presacral fascia of the sacral promontory and sigmoidopexy onto the anterior abdominal wall) in treatment of complete rectal prolapse in children using laparoscopy. Methods: This prospective study was conducted on 12 children with persistent complete rectal prolapse who failed to respond to adequate conservative measures from July 2015 to July 2016. The technical details of the procedure are described. Patients were followed up for at least 6 months and were assessed clinically and radiologically for continence and constipation using the appropriate scoring systems. Results: Twelve patients were included, 8 females and 4 males, laparoscopic rectopexy and sigmoidopexy were done for all cases. The mean duration for surgery was $58.42 \mathrm{~min}$. No intraoperative complications recorded. One case $(8.3 \%)$ had partial thickness recurrence and 1 case had skin stitch sinus. No postoperative constipation nor incontinence was observed. Conclusion: The laparoscopic rectopexy and sigmoidopexy is an effective approach for the treatment of refractory complete rectal prolapse in children. The 3-point fixation proved efficient in controlling rectal prolapse in children with minimal complications.
\end{abstract}

This is an open access article licensed under the terms of Creative Commons Attribution 4.0 International License (https://creativecommons.org/licenses/by/4.0/), which permits unrestricted use, distribution, and reproduction in any medium, as long as the original author is credited and the new creations are licensed under the identical terms.

For reprints contact: service@oaepublish.com

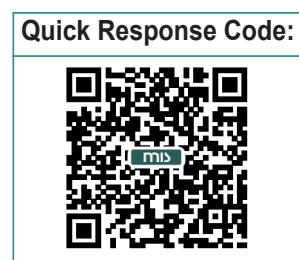




\section{INTRODUCTION}

Complete rectal prolapse is defined as the protrusion of all layers of the rectal wall through the anal canal. If prolapse of the rectal wall occurred but does not protrude through the anus it is called "rectal intussusception" or "occult rectal prolapse". Complete rectal prolapse should be distinguished from mucosal prolapse, in which mucosal prolapse the only protrusion is the anal mucosa. In children it usually presents as a self-limiting disorder. The peak incidence is between 1 and 3 years of age and it has equal gender distribution. ${ }^{[1-3]}$

Prolapse can be either partial or complete. The majority of cases have no obvious cause, though in western countries it is usually related to excessive straining, constipation, cystic fibrosis or functional defecation disorder, however, gastroenteritis and parasitic infestation associated with rectal prolapse are commonly seen in third-world countries. ${ }^{[4-6]}$

Conservative measures are considered the first line of treatment in all cases of rectal prolapse in children. It proved to be effective in controlling prolapse in most of primary cases. ${ }^{[7]}$ This includes reduction of the prolapse to decrease edema, bleeding and mucosal ulceration. Supporting the perineum during defecation, defecation in recumbent position, and taping the buttocks to prevent the prolapse from recurring spontaneously, may be helpful as well as proper toilet training. Medical and dietary treatment for the predisposing factors with stool softeners, laxatives, adequate fluid intake and high fiber diet for treatment of constipation and avoidance of straining is important. Further, treatment for parasitic infestations and investigation and treatment for malabsorption and cystic fibrosis are among conservative measures.

Surgical treatment should be reserved for cases resistant to adequate conservative measures. Surgical treatment includes a wide range of abdominal or perineal surgical operations. With such a wide variety of treatment options and variable success rates, the optimal treatment for this condition in children is widely controversial. ${ }^{[3,4,7,8]}$

The aim of surgical management of full-thickness prolapse is to eliminate the external prolapse of the rectum, improve bowel function, and reduce the incidence of recurrence. ${ }^{[9,10]}$ Presacral rectopexy has become one of the successful approaches to the treatment of rectal prolapse. This technique has many modifications in addition to the use of different types of mesh. However, all involved mobilization and upward fixation of the rectum to the presacral fascia and was done by open or laparoscopic approach. Laparoscopy is gaining wide acceptance in the management of rectal prolapse in children. ${ }^{[6,7,11,12]}$

The laparoscopic approach facilitates many minimally invasive techniques that proved to be effective and simple with many advantages including better cosmesis, rapid return of intestinal motility, short hospital stay, low morbidity and low recurrence rate. We propose our concept of laparoscopic rectopexy and sigmoidopexy by 3-point fixation is a new concept for management of complete persistent rectal prolapse.

\section{METHODS}

From July 2015 to July 2016, a total of 65 children with complete rectal prolapse presented to Pediatric Surgery Department in El Shatby University Hospital were enlisted and evaluated. Detailed history from all patients including: age, gender, weight, history of the presenting symptoms, duration of the prolapse. Associated symptoms e.g. bleeding, constipation, incontinence, straining and ulcers, associated comorbidities as ectopia vesicae, nutritional history and history of previous operations for treatment of rectal prolapse such as injection sclerotherapy and the Thiersch operation. They were subjected to clinical examination in the form of general examination, inspection of perineum for externally visible prolapse, and rectal examination to detect ulcers and polyps, degree of prolapse and prolapse length. Routine laboratory investigations and stool analysis for parasitic infestation was performed.

Conservative measures were attempted in all cases in the form of proper toilet training, reduction of the prolapsed bowel, adhesive strapping of the buttocks, avoidance of squatting position on defecation, adequate fluid intake, high fiber diet, stool softeners and laxatives for 3 months. Twelve of 65 cases were filtered. The inclusion criteria included cases with complete persistent rectal prolapse more than 3 months with optimum conservative measures, recurrent or persistent prolapse after previous trials of injection sclerotherapy or other previous surgery for rectal prolapse correction. The exclusion criteria were grade I prolapse, complete rectal prolapse grade II responding to conservative measures and patients with spinal or sacral anomalies.

Cystic fibrosis testing was deemed unnecessary due to the extremely low incidence in our population. All children with persistent rectal prolapse after successful treatment of secondary causes, as well as those who had recurrence after previous surgery, underwent Laparoscopic rectopexy and sigmoidopexy. Patients 


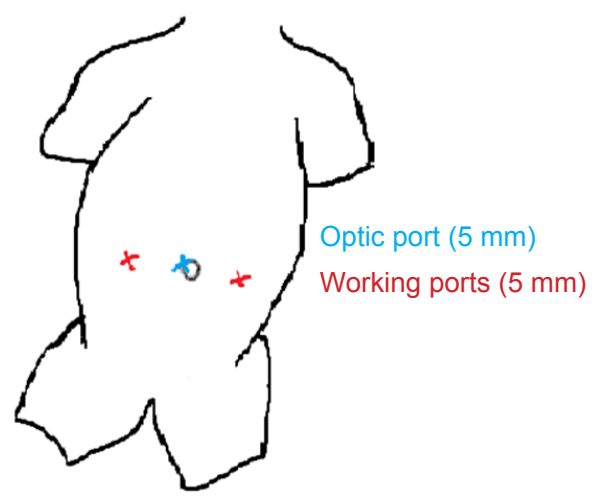

Figure 1: Trocars placement sites

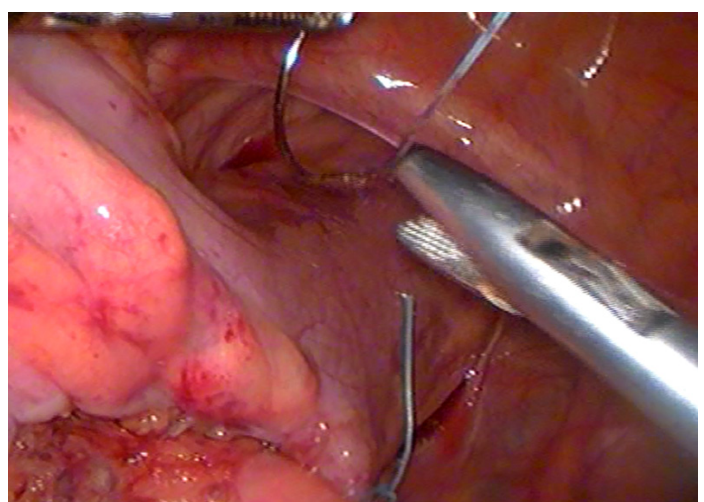

Figure 2: Retrorectal dissection with fixation of the rectum to the periosteum of the sacral promontory

were only allowed clear fluids for $24 \mathrm{~h}$ before surgery and had laxative suppositories the night before surgery.

\section{Operative details}

Each patient was informed about the operation, the possible complications and also the possibility of conversion to open surgery was explained to each patient. A written consent was taken from each patient before the operation. The procedure was performed with the patient under general anesthesia and in supine position. After insertion of a suitable Foley's catheter to empty the bladder and monitor the urine output, three $5 \mathrm{~mm}$ ports were used [Figure 1] for mobilization, retrorectal dissection and bowel fixation: an umbilical port for the scope and two lateral working ports in the midclavicular line at the level of the umbilicus. The table was tilted head down to evacuate the pelvis and allow better exposure of the rectum. After reduction of the prolapsed bowel, the peritoneum was incised on the right side of the rectum starting from the peritoneal reflection to the sacral promontory [Figure 2]. The right ureter was identified prior to the peritoneal incision to avoid its injury. The retrorectal space was dissected to the level of the pelvic floor without division of the lateral ligaments [Figure 3]. One to two seromuscular $2 / 0$ Ethibond ${ }^{\circledR}$ sutures were used to suspend the rectum to

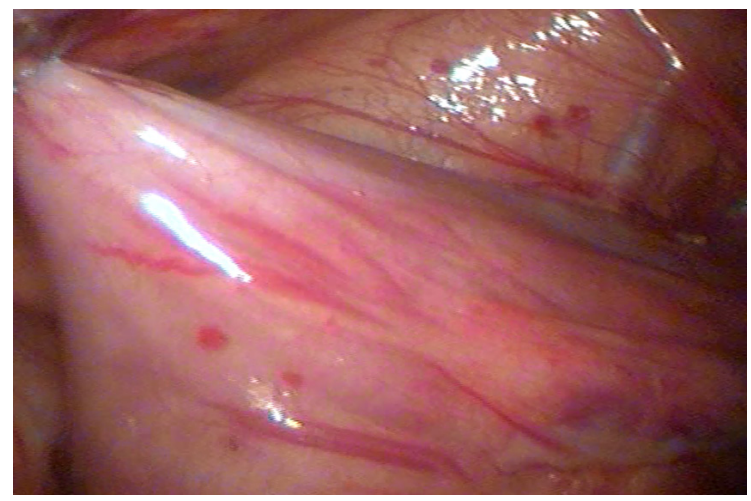

Figure 3: Fixation of the sigmoid colon to the anterior abdominal wall two inches above and medial to the left anterior superior iliac spine

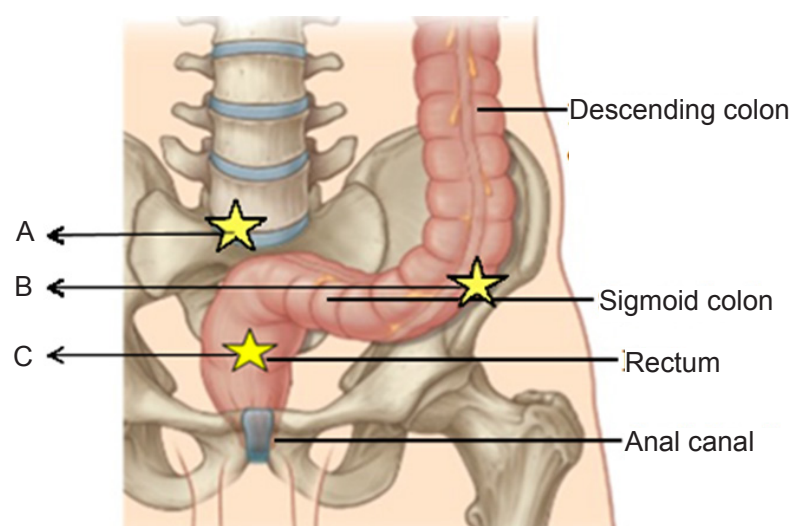

Figure 4: Points of fixation of the rectum and sigmoid colon. A: Rectal fixation to sacral promontory; B: sigmoid fixation to anterior abdominal wall; $\mathrm{C}$ : fibrosis developed by retrorectal dissection

the presacral fascia of the sacral promontory. Another suture was used percutaneously to fix the seromuscular wall of the sigmoid colon to the anterior abdominal wall 2 inches above and medial to the left anterior superior iliac spine suture with the knot buried under the skin [Figure 4]. The operative time, mean hospital stay, operative and postoperative complications and any recurrence were recorded. After discharge a Barium enema was done for all cases 1 month postoperatively to detect any bowel dilatation and delayed bowel evacuation. Patients were followed up in the outpatient clinic at 1, 3 and 6 months after the procedure and then at yearly intervals.

\section{Statistical analysis}

Data were collected using Microsoft Office Excel 2010 (Microsoft Corp.), imported into SPSS modeler and analyzed using IBM ${ }^{\circledR}$ SPSS Statistics 19.0 (IBM Corp.).

\section{RESULTS}

The total number of cases of rectal prolapse presented to the Outpatient Clinic of the Pediatric Surgery Department in El Shatby University Hospital form July 2015 to July 
Table 1: Demographic data of the cases $(n=12)$

\begin{tabular}{lccc|}
\hline Age group & Male, $\boldsymbol{n}(\%)$ & Female, $\boldsymbol{n}(\%)$ & Total, $\boldsymbol{n}(\%)$ \\
\hline$<3$ years & $0(0)$ & $6(75)$ & $6(50)$ \\
3-6 years & $2(50)$ & $2(25)$ & $4(33.3)$ \\
6-9 years & $2(50)$ & $0(0)$ & $2(16.7)$ \\
Total & $4(33.3)$ & $8(66.7)$ & $12(100)$ \\
Mean \pm SD & $6.83 \pm 2.93$ & $1.98 \pm 1.29$ & \\
\hline
\end{tabular}

2016 was 65 cases: 15 cases $(23.1 \%)$ who failed to respond to conservative measures were admitted to Alexandria Pediatric Surgery Department. Two of the 15 were at the age of 2 months and 1 case had huge splenomegaly due to Gaucher disease and they were unfit for laparoscopic management, so were excluded from the study. The remaining 12 cases underwent laparoscopic rectopexy and sigmoidopexy [Table 1].

The mean age of presentation of our cases was 3.32 \pm 2.70 years, $8(66.7 \%)$ females and $4(33.3 \%)$ males with a female to male ratio of $2: 1$. The median duration of symptoms was 5.5 months.

All 12 cases (100\%) were complaining of frequent "bowel prolapse" of variable length ranged between 4 and 15 $\mathrm{cm}$ with a mean of $7.0 \pm 3.02 \mathrm{~cm}$, most frequently falling in the range of $5-7 \mathrm{~cm}, 8$ of them $(66.7 \%)$ presented by persistent continuous prolapse that descends immediately after reduction and 4 cases (33.3\%) presented by prolapse that occurs on straining and after every defecation with mandatory manual reduction from the start of their complaint. Bleeding per rectum was a complaint in 4 cases (33.3\%) only with prolapse. Constipation was present in 3 cases $(25 \%)$. The mean Wexner/Agachan score ${ }^{[13]}$ was $17.3 \pm 1.52$ (range 1619). Persistent straining was present in 6 cases $(50 \%)$ with or without constipation and 2 of which were known ectopia vesicae patients and 1 case was complaining of urinary bladder stones. Solitary rectal ulcer was present in 1 case $(8.3 \%)$. Two cases had ectopia vesicae $(16.7 \%)$. Fecal incontinence was not encountered in any case. Four cases (33.3\%) had previous Thiersch procedure that failed 2 weeks to 1 month postoperatively and 1 case had undergone a repeat Thiersch. The mean operative time was $58.42 \pm 22.75 \mathrm{~min}$.

There were no reported intraoperative complications. All cases were completed laparoscopically without conversion to open surgery. All patients achieved full recovery, oral feeding started as soon as return of bowel motion with mean hospital stay of $2.50 \pm 0.52$ days.

The mean follow-up duration was $9.17 \pm 3.86$ months. Postoperative complications were skin stitch sinus in 1 case $(8.3 \%)$ at the site of sigmoidopexy which was treated by removing the stitch. Recurrence was reported

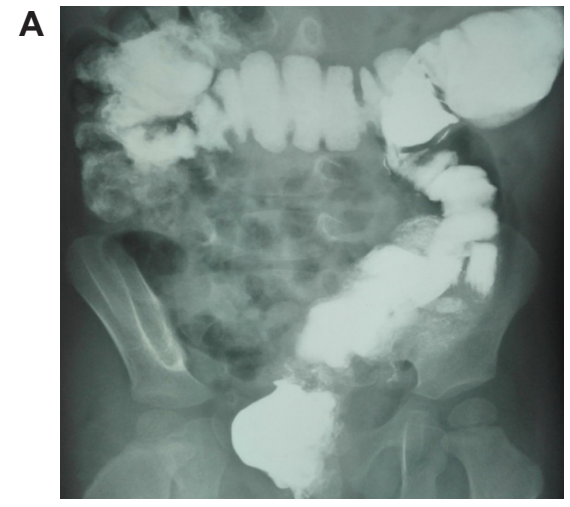

B

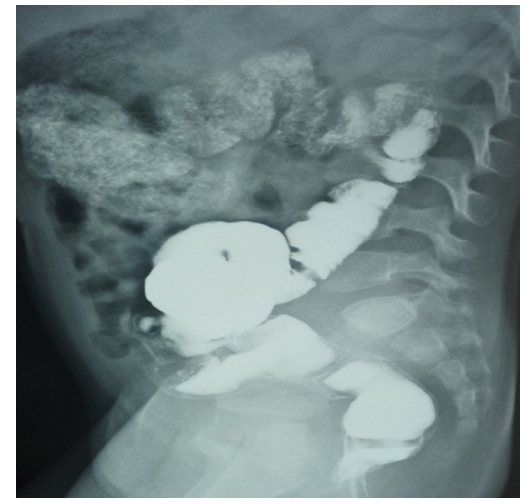

C

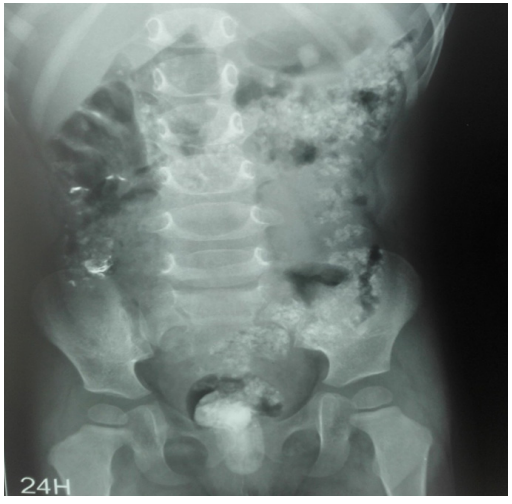

Figure 5: (A) Barium enema postoperative (postero-anterior view); (B) barium enema postoperative (lateral view); (C) barium enema postoperative delayed film (postero-anterior view)

in 1 case $(8.3 \%)$. The recurrence occurred 1 week after the repair as a partial mucosal prolapse and was managed conservatively. Bleeding resolved completely $(100 \%)$ after correction of prolapse. Constipation neither recurred in the complaining cases nor complicated new ones during the follow-up period. The mean Wexner/ Agachan score ${ }^{[13]}$ was $6.83 \pm 1.64$. Incontinence didn't complicate any of our cases during the follow-up. The mean Kelly's score ${ }^{[14]}$ was $5.58 \pm 0.51$ (range $5-6$ ). Barium enema was done for all cases in our study 1 month after surgery and showed no colonic dilatation and no residual barium in their bowel [Figure 5].

\section{DISCUSSION}

Rectal prolapse is a common condition in children and 
Table 2: Comparison of results of different techniques for treatment rectal prolapse in children

\begin{tabular}{|c|c|c|c|}
\hline Studies & No. of cases & Technique & Success rate (\%) \\
\hline Wyatt ${ }^{[21]}$ & 21 & Posterior sagittal (mesh fixation) & 95.2 \\
\hline Ashcraft et al. ${ }^{[18]}$ & 46 & Posterior sagittal (levator repair + suspension) & 89 \\
\hline Petren ${ }^{[22]}$ & 26 & Ekehorn (transanal suture rectosacropexy) & 100 \\
\hline Nazem et al. ${ }^{[3]}$ & 41 & Perineal mesh rectopexy with sterile talc & 98.4 \\
\hline Sander et al..$^{[10]}$ & 56 & Ekehorn (transanal suture rectosacropexy) & 100 \\
\hline Ismail et al. ${ }^{[19]}$ & 40 & LSRP with sigmoid fixation & 100 \\
\hline Shalaby et al. ${ }^{[7]}$ & 52 & Laparoscopic mesh rectopexy & 100 \\
\hline Koivusalo et al. ${ }^{[17]}$ & 16 & LSRP $=6$ cases $;$ PSRP $=10$ cases & $100 ; 75$ \\
\hline Laituri et al. ${ }^{[23]}$ & 10 & PSRP & 70 \\
\hline Puri $^{[15]}$ & 19 & LSRP & 95 \\
\hline Montes-Tapia et al. ${ }^{[24]}$ & 2 & LSRP with sigmoid fixation & 100 \\
\hline Awad et al. ${ }^{[6]}$ & 20 & LSRP & 90 \\
\hline Potter et al..$^{[12]}$ & 19 & LSRP & 95 \\
\hline Gomes-Ferreira et al. ${ }^{[11]}$ & 8 & Laparoscopic modified Orr-Loygue & 100 \\
\hline Our study & 12 & LSRP with sigmoid fixation & 91.7 \\
\hline
\end{tabular}

LSRP: laparoscopic suture rectopexy; PSRP: posterior sagittal rectopexy

is usually self-limiting as it mostly occurs as a primary condition without any predisposing factors. Surgery is reserved for a very limited number of cases with persistent prolapse not responding to conservative measures. These cases can develop ulceration and bleeding with frequent admissions to the hospital due to irreducible prolapse and/or poor compliance of patients or their parents with conservative treatment.

Laparoscopic approach for rectal prolapse facilitates many simple and effective minimally invasive techniques that carry low morbidities and low recurrence rate together with short hospital stay and better cosmesis. Of the various laparoscopic techniques, we chose the 3 -point fixation of the rectosigmoid colon. Fibrosis developed by retrorectal dissection, rectopexy to the periosteum of the sacral promontory and sigmoidopexy onto the abdominal wall.

Our study was conducted on 12 cases, 8 females and 4 males with a male to female ratio of 1:2. Randall et al. ${ }^{[2]}$ in their study reported that there was no sex difference (6 females and 5 males), however, Awad et al., ${ }^{[6]}$ Shalaby et al., ${ }^{[7]}$ Potter et al. ${ }^{[12]}$ and Puri ${ }^{[15]}$ in their studies reported that male patients outnumbered female ones. The age incidence in our series ranged from 6 months to 9 years with a peak of $1-3$ years [Table 2].

Conservative measures are the key for treatment of rectal prolapse and it should be tried in all cases. In the present study, the success rate of conservative measures was $76.9 \%$. Generally, surgical intervention is only recommended after failure of conservative measures. However, this period varies depending on the severity of prolapse (frequent manual reductions, non-compliant patient/parents, length of prolapse, ulceration, and impending gangrene).
Chronic constipation is by far the most common prolapse association as noticed by many authors. ${ }^{[2,16,17]}$ However, persistent straining was found to be the second most common presentation in the present study which may or may not be accompanied by constipation. Straining was found in 6 of our cases $(50 \%) ; 2$ cases with ectopia vesicae, 1 case with multiple urinary bladder stones and the last 3 cases was associated with constipation. Chronic constipation together with hard stool causing more straining, which in turn causes increase in the intra-abdominal pressure. The increased intra-abdominal pressure acts upon the less developed protecting mechanisms causing the rectum to prolapse.

All of our 12 patients were essentially presenting with a full-thickness rectal prolapse either primary or secondary so all of them underwent laparoscopic rectopexy and sigmoidopexy. The concept behind is to create 3-point fixation, 2-point fixation to the rectum by suture and fibrosis developed after dissection and the 3rd fixation point is at the sigmoid colon thus preserving and restoring of the normal rectosigmoid angle preventing the occurrence of intussusception at a higher points, proposed as a cause of failure as reported in other studies ${ }^{[18]}$ while adding additional fixation to the bowel. Sigmoid fixation also resolved the problem of rectosigmoid redundancy, a major cause of recto anal intussusception.

The mean operative time in our series was $58.42 \pm$ $22.75 \mathrm{~min}$, similar to the mean time in Ismail et al. ${ }^{[19]}$ (60 min), but less than the mean time in other studies using laparoscopy. ${ }^{[6,11,12,15]}$

The overall recurrence was 1 case out of 12 cases (8.3\%). It was mucosal prolapse which improved over 6 weeks by conservative measures in the form of 
sitz bath, oral laxatives and anti-inflammatory drugs. These data are similar to the results of other surgical procedures including Ekehorn rectosacropexy, modified Orr-Loygue mesh rectopexy, posterior repair and suspension, sclerotherapy and transabdominal rectopexy with omental flap and laparoscopic mesh rectopexy. They have reported excellent results with little morbidity. ${ }^{[7,10,11,18,20]}$

Koivusalo et al. ${ }^{[17]}$ had no recurrence in his cases who underwent laparoscopic suture rectopexy (LSRP). Also Puri[15] reported 1 case recurrence out of 19 cases during the follow-up for his cases. Rintala and Pakarinen ${ }^{[1]}$ preferred laparoscopic rectal fixation to the anterior sacrum without using mesh, and they claimed that this approach was successful in many patients. In Ismail et al.., ${ }^{[19]}$ LSRP was done in 8 of 40 cases with excellent success rate and low morbidities and no recurrence. The recurrence rate in Awad et al. ${ }^{[6]}$ using suture rectopexy was 1 case in 20 patients $(5 \%)$. Randall et al. ${ }^{[2]}$ reported failure in all of his cases treated by laparoscopic suture rectopexy. The cause of failure in his series may be attributed to the fact that it was conducted on a different cohort of patients who were older (median age at operation was 14 years). Potter et al. ${ }^{[12]}$ reported also 1 case $(5 \%)$ full thickness recurrence and mucosal prolapse in 2 cases (11\%).

Correction of the prolapse also helped in controlling the associated symptoms: bleeding completely disappeared, improvement of constipation was noticed during the outpatient visits and the postoperative Barium enema showed no bowel dilation, no bowel kink and no residual dye indicating no delayed bowel emptying.

As regards incontinence, it did not complicate any of our cases preoperatively and was not encountered in our cases postoperatively. The mean Kelly's score ${ }^{[14]}$ among our cases was 5.58 indicating good continence. On the other hand, constipation, which was a major contributing factor in our cases, improved postoperatively in cases presented with constipation and it did not complicate any of our cases postoperatively. The mean Wexner/ Agachan score ${ }^{[13]}$ preoperatively was 17.3 (range 1619) which improved postoperatively to a mean of 6.83 (range 5-10). Koivusalo et al. ${ }^{[17]}$ reported 2 patients with postoperative constipation. Puri[i15] reported 1 case with postoperative constipation. Ismail et al. ${ }^{[19]}$ reported 1 case of postoperative constipation that was managed conservatively.

Laparoscopic suture suspension of the rectum to the sacrum results in fibrosis due to retro-rectal dissection together with sigmoid fixation to add more support preventing recurrence without exerting undue tension on the bowel that may cause alteration of bowel motility and possible postoperative constipation. Laparoscopic rectopexy and sigmoidopexy is favorable to mesh fixation as it is a easier technique, has shorter operative time, more cost-effective and without complications of the mesh (e.g. pelvic abscess and rectal kink over the edge of the mesh causing constipation). In addition, laparoscopic rectopexy and sigmoidopexy showed almost equal recurrence rate. ${ }^{[2,6,7,11,12,16]}$

If compared to suture rectopexy alone, laparoscopic rectopexy and sigmoidopexy has lower recurrence rate, almost equal operative time, nearly similar morbidities with less post-operative constipation. ${ }^{[6,12,17]}$

In conclusion, we believe that our technique of laparoscopic rectosigmoidopexy is an effective and efficient technique for treating children with persistent full-thickness rectal prolapse having a low recurrence rate and minor complications. The anatomical restoration of the normal rectosigmoid angle is credited to our 3-point fixation concept. We propose the new concept of 3-point fixation in the surgical treatment of persistent complete rectal prolapse as a favorable alternative to other more complex open or laparoscopic techniques with inevitably lower efficacy, higher morbidity and lower recurrence rates.

\section{Authors' contributions}

Study conception and design, performing the surgical technique: S. Shehata

Critical revision and assistance in operations: M. Abouheba Acquisition of data, drafting of manuscript: A. Mokhtar

\section{Financial support and sponsorship}

None.

\section{Conflicts of interest}

There are no conflicts of interest.

\section{Patient consent}

Written detailed informed consent was obtained from all parents.

\section{Ethics approval}

The protocol of work was approved by the ethical committee of our hospital.

\section{REFERENCES}

1. Rintala RJ, Pakarinen M. Other disorders of the anus and rectum, anorectal function. In: Grosfeld JL, O’Neill JA, Fonkalsrud EW, Coran A, editors. Pediatric surgery. 6th ed. Philadelphia: MosbyElsevier; 2006. p. 1595-6.

2. Randall J, Gallagher H, Jaffray B. Laparoscopic rectopexy for externa 
prolapse in children. J Pediatr Surg 2014;49:1413-5.

3. Nazem M, Hosseinpour M, Farhadi M. Perineal mesh rectopexy with sterile talc in children with rectal prolapse. Eur J Pediatr Surg 2010;20:321-4.

4. Siafakas C, Vottler TP, Andersen JM. Rectal prolapse in pediatrics. Clin Pediatr (Phila) 1999;38:63-72.

5. Gilman RH, Davis C, Fitzgerald F. Heavy Trichuris infection and amoebic dysentery in Orang Asli children. A comparison of the two diseases. Trans R Soc Trop Med Hyg 1976;70:313-6.

6. Awad K, El Debeiky M, AbouZeid A, Albaghdady A, Hassan T, Abdelhay S. Laparoscopic suture rectopexy for persistent rectal prolapse in children: is it a safe and effective first-line intervention? $J$ Laparoendosc Adv Surg Tech A 2016;26:324-7.

7. Shalaby R, Ismail M, Abdelaziz M, Ibrahem R, Hefny K, Yehya A, Essa A. Laparoscopic mesh rectopexy for complete rectal prolapse in children: a new simplified technique. Pediatr Surg Int 2010;26:807-13.

8. Karulf RE, Madoff RD, Goldberg SM. Rectal prolapse. Curr Probl Surg 2001;38:771-832.

9. Senagore AJ. Management of rectal prolapse: the role of laparoscopic approaches. Semin Laparosc Surg 2003;10:197-202.

10. Sander S, Vural O, Unal M. Management of rectal prolapse in children: Ekehorn's rectosacropexy. Pediatr Surg Int 1999;15:111-4.

11. Gomes-Ferreira C, Schneider A, Philippe P, Lacreuse I, Becmeur F. Laparoscopic modified Orr-Loygue mesh rectopexy for rectal prolapse in children. J Pediatr Surg 2015;50:353-5.

12. Potter DD, Bruny JL, Allshouse MJ, Narkewicz MR, Soden JS, Partrick DA. Laparoscopic suture rectopexy for full-thickness anorectal prolapse in children: an effective outpatient procedure. $J$ Pediatr Surg 2010;45:2103-7.

13. Agachan F, Chen T, Pfeifer J, Reissman P, Wexner SD. A constipation scoring system to simplify evaluation and management of constipated patients. Dis Colon Rectum 1996;39:681-5.

14. Kelly JH. The clinical and radiological assessment of anal continence in childhood. Aust N Z J Surg 1972;42:62-3

15. Puri B. Rectal prolapse in children: laparoscopic suture rectopexy is a suitable alternative. J Indian Assoc Pediatr Surg 2010;15:47-9.

16. Flum AS, Golladay ES, Teitelbaum DH. Recurrent rectal prolapse following primary surgical treatment. Pediatr Surg Int 2010;26:42731.

17. Koivusalo A, Pakarinen M, Rintala R. Laparoscopic suture rectopexy in the treatment of persisting rectal prolapse in children: a preliminary report. Surg Endosc 2006;20:960-3.

18. Ashcraft KW, Garred JL, Holder TM, Amoury RA, Sharp RJ, Murphy JP. Rectal prolapse: 17-year experience with the posterior repair and suspension. J Pediatr Surg 1990;25:992-4.

19. Ismail M, Gabr K, Shalaby R. Laparoscopic management of persisten complete rectal prolapse in children. J Pediatr Surg 2010;45:533-9.

20. Fahmy MA, Ezzelarab S. Outcome of submucosal injection of different sclerosing materials for rectal prolapse in children. Pediatr Surg Int 2004;20:353-6.

21. Wyatt AP. Perineal rectopexy for rectal prolapse. $\mathrm{Br} J$ Surg 1981;68:717-9.

22. Petren G. The end-results of Ekehorn's rectopexy for rectal prolapse in children. Acta Chir Scand 1925;59:287-98.

23. Laituri CA, Garey CL, Fraser JD, Aguayo P, Ostlie DJ, St Peter SD Snyder CL. 15-Year experience in the treatment of rectal prolapse in children. J Pediatr Surg 2010;45:1607-9.

24. Montes-Tapia F, Cura-Esquivel I, Garza-Luna U, Martinez-Flores G Munoz-Maldonado G, Abrego-Moya V. Sigmoid fixation associated with rectopexy using a laparoscopic approach could prevent relapse of rectal prolapse in pediatric patients with spinal dysraphia. $J$ Pediatr Surg 2008;43:1551-3. 